each end of the calc crystal so as to make the new end-faces almost co-planar with a principal plane of section, and the crystal is cut through along the other diagonal of the sides. The results may be tabulated thus :-

$$
\text { Ordinary Nicol }
$$

$$
\text { Reversed }
$$$$
\begin{aligned}
& \text { shortened } \\
& \text { Nicol }
\end{aligned}
$$

Obliquity of end-face

Angle between end-face and crys. tallographic axis

Angle between balsam-film and crystallographic axis

71

69

45

The effect is to throw the blue-iris limit right back, to shorten the prism, and to widen the field. In the discussion that followed, Prof. Stokes remarked that there was no dearth of Iceland spar in Iceland, but that the supply had been limited through ignorance of the extent of the demand. The mine had, however, been bought by the Icelandic Government, and a plentiful supply might therefore be expected.

\section{THE SYMPATHETIC NERVOUS SYSTEM ${ }^{1}$}

THE lecturer commenced by giving a short sketch of Bichat's views of the division of life into organic and animal life, and pointed out how that division naturally led to the conception of two separate central nervous systems, the one, the sympathetic, to which all the organic functions are to be referred, the other, the cerebro-spinal, regulating the animal functions. He then pointed out how Remak's discovery of a special kind of nerve-fibre the non-medullated nerves-associated only with the ganglia of the sympathetic system, tended strongly to confirm Bichat's teaching of the existence of two separate central nervous systems in the human body, each of which communicated with the other by means of its own special kind of nerve-fibres ; the cerebro-spinal supplying the sympathetic system with white medullated fibres, and the sympathetic supplying the cerebro-spinal with gray or gelatinous non-medullated fibres. He then continued as follows:-

Even at the present day the teaching of Bichat still very largely holds its ground. It is true that the tendency of modern physiology is to increase the number of centres of action for the organic nerves, which exist in the cerebro-spinal central axis, and therefore to do away with the necessity for a separate independent sympathetic nervous system, yet the automatic actions of isolated organs such as the heart, and the existence of special nerve-fibres in connection with this system, still induce the neurologists of the present day to place the sympathetic nervous system on an equality with the brain or spinal cord. In this lecture to-night I hope to give the death-blow to Bichat's teaching, and to prove to you that the whole sympathetic system is nothing more than an outflow of visceral nerves from certain nerve-centres in the cerebro-spinal system, the ganglia of which are not confined to one fixed position, as is the case with the ganglia of the posterior roots, but have travelled further away from the central axis.

I do not propose to-night to deal with the argument for the independence of the sympathetic nervous system, which is based upon the automatism of such isolated organs as the heart; I have already in various papers given the reasons and arguments why I look upon such automatic movements as due to the automatism of the cardiac muscular tissue rather than to any action of nerve-cells comparable to the nerve-centres of the spinal cord ; I shall deal entirely with the anatomical argument, and show you step by step how the nerve-fibres which constitute the sympathetic system can be traced to their origin in the central cerebro spinal axis.

Evidently, in endeavouring to determine by anatomical means whether the sympathetic and cerebro-spinal systems are in reality independent of one another, our attention must necessarily be especially concentrated upon the nature of the connecting-link between the two systems, i.e. upon the nature of the rami communicantes. Largely owing to the pre-conceived notions of anatomists, you will find that the rami communicantes are arranged symmetrically in connection with all the spinal nerves of the body. In reality this is far from being the case; the rami communicantes of the thoracic nerves differ from those above them, i.e. of the cervical nerves, and from those below them, I Abstract of Lecture at the Royal Institution on June 4, $x 886$, by
Walter H. Gaskell, M.D., M.A., F.R.S. i.e. of the Iumbar nerves, in two important particulars : in the first place the corresponding sympathetic ganglion is connected with each thoracic nerve by two rami communicantes; and secondly, these two rami differ in colour, one being gray, i.e. composed almost entirely of non-medullated nerves, and the other white, i.e. composed essentially of medullated nervefibres.

This double nature of the ramus communicans is confined to the region lying between the two large plexuses which supply the anterjor and posterior extremities, viz. the brachial, lumbar, and sciatic plexuses; the rami communicantes to the lower cervical and first thoracic nerves, as well as those to the nerves forming the anterior crural and the sciatic, are, on the other hand, single, and are composed only of gray rami. In other words, the sympathetic chain is connected with the central nervous system by means of white rami communicantes only between the second thoracic and second lumbar nerves.

Further, I have been able to trace both the white and gray rami in their journey to the spinal cord by means of consecutive sections of osmic acid preparations, and have found that the gray rami pass out of the sympathetic ganglion as a single nerve, and then ramify in the connective tissue about the vertebral foramina, a portion only reaching the spinal nerve-trunk; the gray fibres of this portion pass mainly along the nerve peripherally, the few which pass centrally never reach the spinal cord, but pass out with the connective tissue which lies in between the medullated nerve-fibres of the anterior and posterior roots, to ramify over and to supply the blood-vessels of the various membranes which inclose the spinal cord.

In fact the gray rami communicantes are peripheral nerves, which partly supply the vertebræa and the membranes of the cord, and partly pass to their destination in the same direction as the efferent fibres of the spinal nerve itself.

So far then I come to these conclusions :-

(1) The sympathetic does not send non-medullated fibres into the cerebro-spinal system, because these fibres all pass out of the nerve-roots before they reach the spinal cord.

(2) White or meduilated nerve-fibres constitute the only link between the sympathetic and cerebro-spinal systems, constituting the white rami communicantes.

(3) Consequently the connection between these two nervous systems is limited to the region of white rami communicantes, i.e. to the region between the second thoracic and second lumbar nerves.

Further, these conclusions are borne out when we attempt to follow the white rami commnnicantes into the central spinal axis by means of their structural peculiarities; sections of osmic preparations show that each white ramus is composed chiefly of very small medullated nerve-fibres, varying in size from $\mathrm{I} \cdot 8 \mu$ to $3^{\cdot} 6 \mu$, very much smaller, therefore, than the large medullated nerves which form the bulk of the anterior roots of the spinal nerves, these latter varying between $14 \mu$ to $20 \mu$ or even larger. Clearly then the fibres of the white ramus communicans ought to show very conspicuously among the large fibres of the anterior roots whenever they are present in those roots. I have cut sections of the anterior roots of all the spinal nerves in the dog; and have found, as I show you on this screen, that these very fine medullated nerve-fibres make their appearance for the first time in the anterior roots of the second thoracic nerve; they are found in large quantities in all the anterior roots between the second thoracic and second lumbar, and then again the anterior roots immediately below the second lumbar are free from such groups of very fine fibres. We see then that exactly corresponding to the presence of white rami communicantes in the thoracic region we find groups of characteristic fine medullated fibres existing in the anterior roots, fibres which clearly form part of the white ramus communicans, and confirm by their presence the conclusion already arrived at, viz. that the nerves which pass from the spinal cord into the sympathetic system are limited to the thoracic region of the cord.

We can now go a step further and argue in the reverse direction that the presence of groups of these very fine medullated fibres in the anterior roots of any nerve implies the existence of nerve-fibres belonging to the same system as the white rami communicantes or rami viscerales, as we may now call them. Examination shows how just is this argument, for I find that the same groups of fine nerve-fibres suddenly appear again in the anterior roots of the second and third sacral nerves, and can be traced into that well-known nerve which passes from the second and third sacral nerves into the hypogastric plexus to 
supply the rectum, bladder, and reproductive organs; a nerve, therefore, which may be looked upon as the white ramus communicans of the sympathetic ganglia which form the hypogastric plexus.

Again, in the cervical region, although such groups of fine fibres are absent from the anterior roots of all the cervical nerves, yet they form a conspicuous part of the upper roots of the spinal accessory nerve, and upon tracing them outwards I find that they separate entirely from the large fibres of the accessory which form its external branch to pass as the internal branch into the ganglion trunci vagi (Fig. 2). Here, then, we see in the upper cervical region that the internal branch of the spinal accessory nerve is formed on the same plan as a white ramus communicans, the ganglion belonging to which is the ganglion trunci vagi.

Among the cranial nerves we find, especially in the vagus, glosso-pharyngeal, and chorda tympani, groups of fine nervefibres belonging to the same system. We can therefore say that the communication between the so-called sympathetic and cerebro-spinal systems is not symmetrical throughout, but consists of three distinct outflows of characteristic visceral nerves, viz. : (I) cervico-cranial ; (2) thoracic ; (3) sacral ; the break of continuity corresponding to the exit of the nerve plexuses which supply the upper and lower extremities.

These medullated visceral nerves then pass out from the central nervous system into the various ganglia of the sympathetic, and it is possible that these latter ganglia bear the same kind of relation to them as the ganglia on the posterior roots bear to the sensory nerves. Before, however, we can accept this view, it is absolutely necessary to account for the non- medullated nerves which arise from the sympathetic ganglia Now it is hopeless to follow, by anatomical means, any special nerve-fibre through the confusion of a ganglion. What we cannot effect by anatomical methods we can by physiological. If we find two nerves, one of which enters a ganglion and the other leaves it, and we find their function absolutely the same on both sides of the ganglion, we have a perfect right to conclude that we are dealing with the same nerve in different parts of its course. Thus, in the case of the posterior root ganglion, the same sensory nerves are found on each sicle of the ganglion, although they are in connection with nerve-cells of the ganglion itself.

So also with the sympathetic ganglia: we know, for instance, that the nerves which increase the rate and strength of the heart's beat pass to the ganglion stellatum along the rami communicantes of the second and following thoracic nerves, and we know also that the same nerves pass to the heart from the ganglion stellatum, from the annulus of Vieussens, and from the inferior cervical ganglion. Now, seeing that these nerves are known to pass out of the cord in anterior roots, and from thence into the white rami communicantes of the upper thoracic nerves, it follows that they are medullated in this part of their course, and are to be found among the bundles of very fine medullated nerves which we have seen are characteristic of the anterior roots of this region and of the white rami communicantes.

We can then say with certainty that the accelerator nerves enter the ganglia stellata as fine white medullated nerves. I am also able to say with absolute certainty that the accelerator nerves in that part of their course which lies between the chain of sympathetic ganglia and the heart are entirely composed of

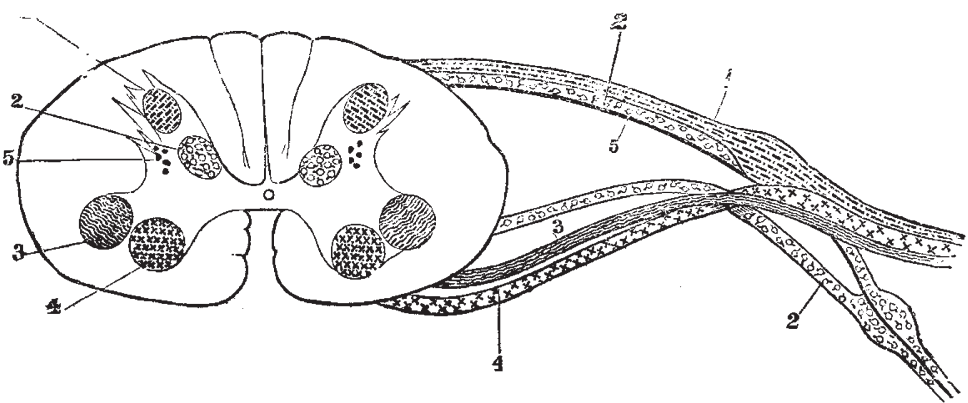

FIG. I.-Diagram of section of spinal cord to show the various groups of nerve-cells in the gray matter, and the formation of a spinal nerve with its sympathetic ganglion. I, cells of posterior horn and somatic sensory nerves. 2 , cells of Clarke's column and ganglionated splanchnic nerves. 3 , cells of lateral horn and non-ganglionated splanchnic nerves. 4, cells of anterior horn and somatic motor nerves. 5, solitary cells of posterior horn and splanchnic sensory nerves.

non-medullated fibres. I know no other bundle of nerve-fibres which is so absolutely free from medullated nerves: in other words, nerve-fibres of the same function enter a sympathetic ganglion as white medullated fibres, and leave it in increased numbers as gray non-medullated nerves.

Throughout we find the same fact-all the vasomotor nerves behave in exactly the same manner as the accelerators of the heart. In all cases the non-medullated fibres of the sympathetic are simply the fine medullated visceral nerves which have passed from the spinal cord in one or other of the three visceral outflows and lost their medullary sheath in their passage through the ganglia of the sympathetic system; together with that loss of medulla they have increased in number by division.

Seeing, then, that the non-medullated (so-called sympathetic) nerve-fibres are throughout modified medullated (so-called cerebro-spinal) fibres, and do not, therefore, arise in the sympathetic ganglia, we may fairly look upon the sympathetic ganglia as bearing the same kind of relation to the visceral nerves that the ganglia of the posterior roots bear to the ordinary sensory nerves. This conception is remarkably confirmed by the observations of Onodi, who has shown that the ganglia of the sympathetic are developed in close connection with the posterior root ganglia, and travel further away from the central axis as the animal grows.

Finally, the meaning of the sympathethic as a simple outflow of ganglionated visceral nerves from certain portions of the spinal cord and medulla oblongata is, to my mind, conclusively settled by the intimate relationship which exists between the structure of the spinal cord and the presence or absence of rami viscerales. In the gray matter of the spinal cord we find, as
Shown in the accompanying diagram, certain well-defined groups of nerve-cells, viz., a, a group of large nerve-cells in the anterior horn ( 4 in Fig. I) ; these are linown to be the origin of ordinary motor-fibres (4); $b$, a group of nerve-cells (3) split off from this and forming the lateral horn ; $c$, a group (2) known as Clarke's column ; and $d$ and $e$, two sets of nerve-cells, (4) and (5), in the posterior horn connected with sensory nerves. All these groups of nerve-cells are found along the whole length of the spinal cord, except those of Clarke's column. Their connection with nerve-fibres of different functions is known, except those of Clarke's column. Thus both sets in the anterior horn are connected with ordinary motornerves; both sets in the posterior horn with ordinary sensory nerves. Now, Clarke's column is limited to certain definite regions of the cord, being conspicuous : firstly, between the second thoracic and second lumbar nerves; secondly, at the top of the cervical region and extending into the cranial region; and, thirdly, an isolated patch in the sacral region. In other words, its cells correspond exactly in position to the distribution of the white rami communicantes, so that, corresponding to the variation of this cell-group, we find variations of the number of very fine medullated fibres in the anterior roots, and we find corresponding variations in the white rami communicantes, which latter, as I have told you, are the only true connections of the cerebro-spinal nerve-centre with the sympathetic. In other words, we have driven home to their origin these visceral nerve-fibres, and we find that they do not arise from any nerve-cells outside the brain and spinal cord, but from a definite nerve-group within the spinal cord.

We can, I think, go further than this, and say, with Bichat, 
that two nerve-systems do exist-the one for organic, and the other for animal, life. These two, however, are not separate and distinct, but form parts of the same central nervous system. Looking at this diagram of the upper cervical region of the cord, we see that the voluntary striped muscles may be divided into two groups, according to their nerve-supply, viz, a group supplied by the anterior (4), and one by the lateral horn of nervecells (3), and we know also that these two groups of nerve-cells separate from one another more and more as we pass into the brain region. So that we find for the muscles of the face a distinct separation of two groups, viz. (I) those which move the eyes and the tongue-these are supplied by nerves which arise from the continuation of the anterior horns; and (2) the muscles of expression and mastication, the nerves of which arise from the continuation of the lateral horn ; and remembering how the smile, the laugh, and the snarl, as well as the action of swallow-

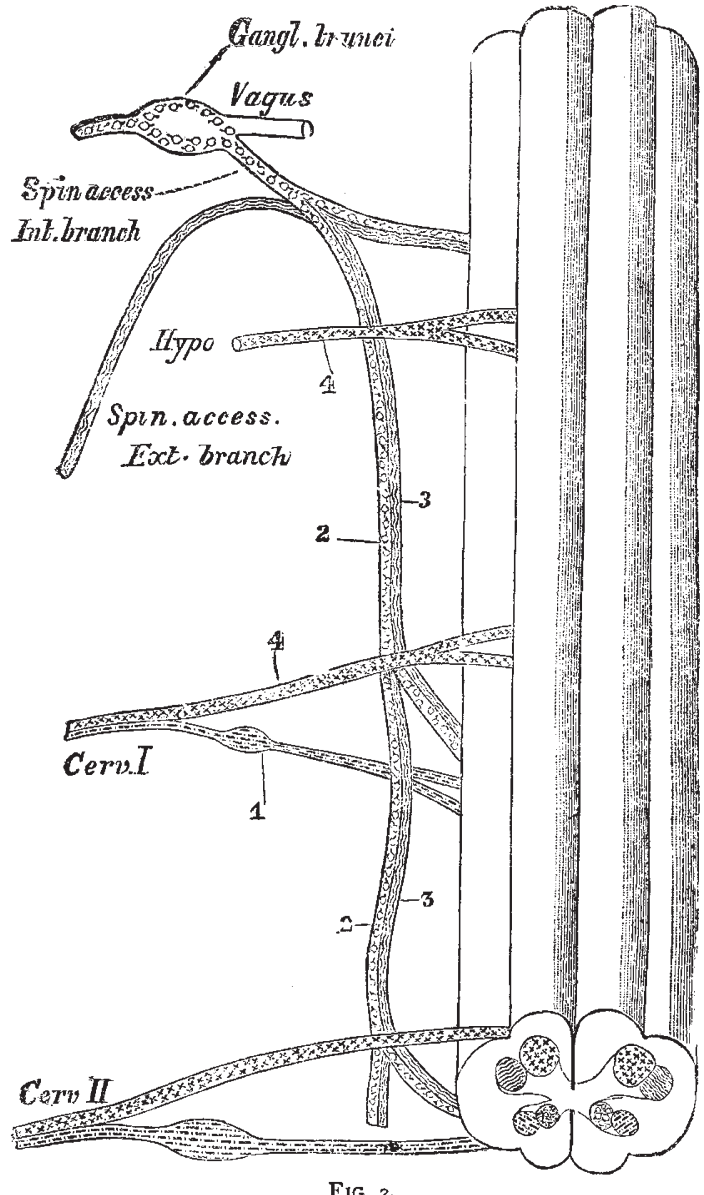

Fig. 2.

ing, are at the bottom only modified respiratory movements, we see that Charles Bell was not so far wrong when he inserted a lateral or respiratory system of nerves in between the anterior and posterior roots. This insertion is actually to be seen at the upper part of the cervical cord (Fig. 2) where a separate nerve is formed by elements which arise laterally, known as the spinal accessory; and what is most striking is this fact, that in this region the fine medullated fibres ( 2 in Fig.) are found only in connection with these lateral motor nerves, and not with the anterior motor, so that not only do these lateral or respiratory tracts supply special muscles with motor nerves, but these motor nerves have a closer relationship to the visceral nerves than other motor nerves. What is true of the upper cervical region is true also of the medulla oblongata. Here, again, the visceral fine medullated nerves are closely connected with the motor fibres which arise from the lateral horn, e.g. the chorda tympani and the facial. Undoubtedly this particular group of muscles has some closer reiationship to the viscera than other trunk muscles, and that relationship is explained immediately if we can accept and extend van Wijhe's investigations, viz. that in the cranial region the muscles which are supplied by the third, fourth, sixth, and twelfth cranial nerves are derived from the myotomes, while the muscles supplied by the seventh and fifth cranial nerves are derived from the lateral plates of mesoblast.

In fact we may look upon the body as composed of two parts -an ontside or somatic part, and an inside or splanchnic part. Each part has its own system of voluntary muscles; each part is supplied by nerves arranged on the same plan, viz. a ganglionated and non-ganglionated portion; and each part has its own individual centres of action, the inside portion of the gray matter of the spinal cord containing the centres for the splanchnic roots $(2,3,5$, in Fig. I), i.e. the centres of organic life; the outlying horns the centres for the somatic roots (I and 4), i.e. centres for the animal life. It is a strange and suggestive fact that these two sets of centres are not arranged symmetrically along the spinal axis, but that two great breaks occur in which the centres of organic life fall into the background in comparison to those of animal life. These two great breaks correspond to the origin of the nerves for the legs and arms, and suggest that the formation of the limbs in the originally symmetrical ancestor of the Vertebrata-i.e. the large outgrowth of somatic elements in two definite portions of the body-caused of necessity a corresponding increase in the centres for animal life, while there was no necessity for a corresponding increase in the centres for organic life. The oldest part of us is undoubtedly the vital part ; those organs and their nervous system by which the mere act of existence is carried on. With these two there may have been originally a symmetrically segmental arrangement of locomotor organs. Such symmetry, however, went for good when it was found more convenient to concentrate the locomotor machinery into the anterior and posterior extremities, and with the asymmetrical arrangement of the locomotor organs disappeared also the symmetry of the central nervous system. This correspondence between the plan of the central nervous system and the development of the extremities is, to my mind, strongly in favour of the view which $I$ have put before you to-night. In conclusion, I thank you for the kindness with which you have listened to me, and hope that I have succeeded in convincing you that Bichat's teaching of an independent sympathetic system is finally dead.

\section{SCIENTIFIC SERIALS}

Revue d'Anthropologie, troisieme série, tome I, I886, Paris. - On the colour of the eyes and hair in different parts of France, by M. Topinard. This paper will form the introduction to a comprehensive work, in which the author proposes to consider the various methods followed in other countries in collecting the necessary data for determining the racial significance of these physical characteristics. In France, where good charts of stature have been drawn up for the several departments, no statistical observations have been made in regard to the colour of the skin, eyes, and hair. This M. Topinard considers at length, both in its significance as a racial characteristic, and in regard to the modifications which it undergoes at various ages, and from different local surroundings. In considering the more or less typical series of colour, the writer draws attention to the extreme rarity in Europe of greenish eyes. In Germany, Prof. Virchow states that, among $6,000,000$ persons, green eyes were noted only in six cases. Chinese annals record, however, that green eyes are met with in parts of Asia ; and Pallas notes a similar fact in regard to Siberia. In concluding his exhaustive résumé of what has been done in other countries, M. Topinard states that he has addressed letters to the members of the French Association for the Promotion of Science, begging their cooperation in the collection of the necessary data for drawing up statistical tables of the relative proportion of the different shades of colour of the eyes and hair in various parts of France.Illyrian anthropology, by Dr. R. Zampa. The author, who is well known for his able contributions to the ethnography of Italy, has turned his attention to the anthropological character of the Illyrian races, who occupied the South Danubian and other eastern trans-Alpine lands, to which tradition points as the original home of the earliest settlers of the Adriatic provinces of central and lower Italy. Dr. Zampa denies that the Illyrians were ever a homogeneous race, and he points out that while those of the north retained throngh the ages the character of 